\title{
An ambitious step to the future desalination technology: SEAHERO R\&D program (2007-2012)
}

\author{
Suhan Kim • Byung Soo Oh • Moon-Hyun Hwang • \\ Seungkwan Hong · Joon Ha Kim $\cdot$ Sangho Lee $\cdot$ \\ In S. Kim
}

Received: 21 January 2011/Accepted: 14 April 2011/Published online: 19 May 2011

(C) The Author(s) 2011. This article is published with open access at Springerlink.com

\begin{abstract}
In Republic of Korea, seawater engineering and architecture of high efficiency reverse osmosis (SEAHERO) research and development (R\&D) program started from 2007 to lead the top seawater reverse osmosis (SWRO) plant technologies for desalination with the fund of US $\$ 165$ million for 6 years including test-bed plant construction. There are three technical strategies for SEAHERO R\&D program called $3 \mathrm{~L}$, which represents large scale, low fouling, and low energy, respectively. Large scale means design, construction, and operation of the largest unit SWRO train [daily water production rate $=8 \operatorname{MIGD}\left(36,000 \mathrm{~m}^{3} /\right.$ day $\left.)\right]$ in the world. Low-fouling strategy targets the decrease of RO membrane fouling by $50 \%$. The specific target for low energy is total energy consumption of whole SWRO plant (including intake,
\end{abstract}

\section{S. Kim}

Department of Civil Engineering, Pukyong National University,

Busan, Korea

B. S. Oh

Emerging Technology Lab., Eco Group, LG Electronics,

Woomyeon, Seocho, Seoul, Korea

\section{M.-H. Hwang · I. S. Kim}

Center for Seawater Desalination Plant, Gwangju, Korea

\section{S. Hong}

School of Civil, Environmental and Architectural Engineering, Korea University, Seoul, Korea

J. H. Kim · I. S. Kim ( $\square)$

School of Environmental Science and Engineering, Gwangju Institute of Science and Technology, Gwangju, Korea e-mail: iskim@gist.ac.kr

S. Lee

School of Civil and Environmental Engineering, Kookmin University, Songbuk-gu, Seoul, Korea pretreatment, SWRO systems, and so on) less than $4 \mathrm{kWh} /$ $\mathrm{m}^{3}$. The core parts for SWRO plant, such as 16 in. diameter RO membrane and energy recovery device, were developed and will soon be introduced to a test-bed including the largest unit SWRO train. The next step of SEAHERO is real field scale test-bed application of the unit technologies developed for the past 4 years (2007-2010) such as strategic pretreatment, energy-saving technology, and reliable system monitoring.

Keywords Desalination - Reverse osmosis - SEAHERO . Large scale $\cdot$ Low fouling . Low energy

\section{Introduction}

Korean government (especially ministry of Land, Transport and Maritime affairs) selected seawater reverse osmosis (SWRO) desalination technology as one of global top 5 technologies which will bloom Korean economy in 2006. Center for Seawater Desalination Plant (CSDP) funded by Korean government launched SEAHERO research and development (R\&D) program from August 31st, 2007. SEAHERO is an abbreviation for seawater engineering and architecture of high efficiency reverse osmosis. SEAHERO R\&D program (SEAHERO hereafter) is targeting to get the top level of SWRO plant technologies in the world and will be carried out with the fund of US $\$ 165$ million for 5 years (Kim et al. 2009a).

SEAHERO consists of four core technology (CT) projects, including development of platform technologies for SWRO plant construction (CT 1: platform technology), development of SWRO membranes and high pressure pump component manufacturing and system optimization technologies (CT 2: plant units localization and system 
Fig. 1 The 3L strategies in SEAHERO R\&D program

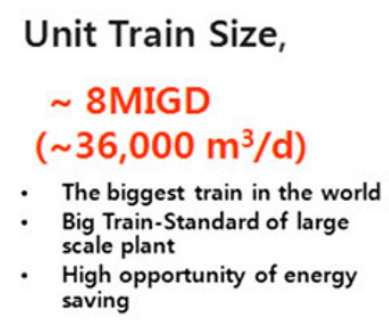

optimization), development of large-scale SWRO plant design and construction technology [CT 3: engineeringprocurement-construction (EPC)], and development of innovative operation and maintenance $(\mathrm{O} \& \mathrm{M})$ technology for large-scale SWRO plant (CT 4: O\&M). More detailed information about the four CTs can be obtained from the official web page of SEAHERO (http://www.seahero.org).

The $3 \mathrm{~L}$ is a title to represent the three main technical strategies as shown in Fig. 1. Each L means large scale plant construction, maintenance by low fouling, and low energy consumption of plant, respectively, which are closely related to the economical efficiency of SWRO desalination plant.

The specific objectives for $3 \mathrm{~L}$ are as follows:

1. Large scale To design and construct the largest unit SWRO train [daily water production rate $=8.0 \mathrm{MIGD}$ $\left(36,000 \mathrm{~m}^{3} /\right.$ day $\left.)\right]$ in the world. The daily production rate of the largest unit train at the moment is 5.2 MIGD, and it is in Point Lisas SWRO plant, Trinidad and Tobago (GWI 2007) and a desalination plant with unit train size of 6.84 MIGD $\left(31,000 \mathrm{~m}^{3} /\right.$ day $)$ will soon be constructed in Antofagasta, Chile (GWI 2009a).

2. Low fouling To reduce membrane fouling by $50 \%$ in terms of silt density index (SDI) and a new fouling index developed through CT 1 project.

3. Low energy To lower energy consumption of whole SWRO plant (including intake, pretreatment, SWRO systems, and so on) less than $4 \mathrm{kWh} / \mathrm{m}^{3}$.

The $3 \mathrm{~L}$ is finally accomplished by designing, constructing, and operating a test-bed, which is defined as a whole system for the real field application of developed unit technologies. The capacity of the test-bed is 10 MIGD $\left(45,000 \mathrm{~m}^{3} /\right.$ day $)$. The test-bed will include an 8 MIGD unit SWRO train, which will be the largest unit train in the world.

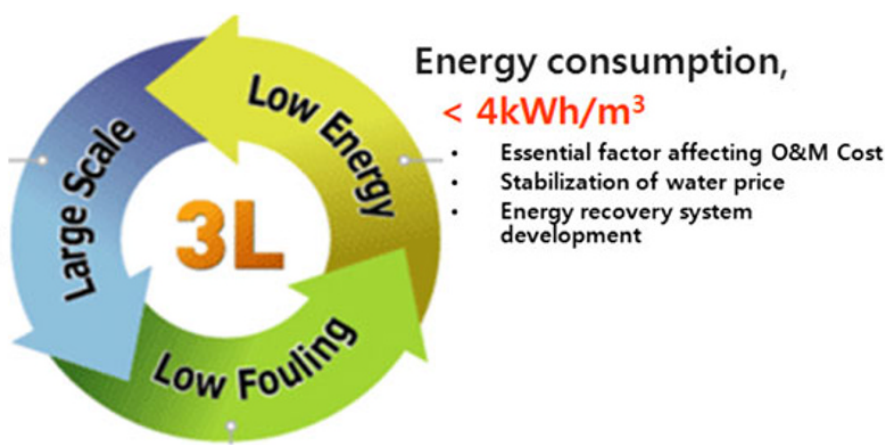

Fouling Reduction as a new

index, $<50 \%$

- Reliability increasing

- Most important factor in SWRO

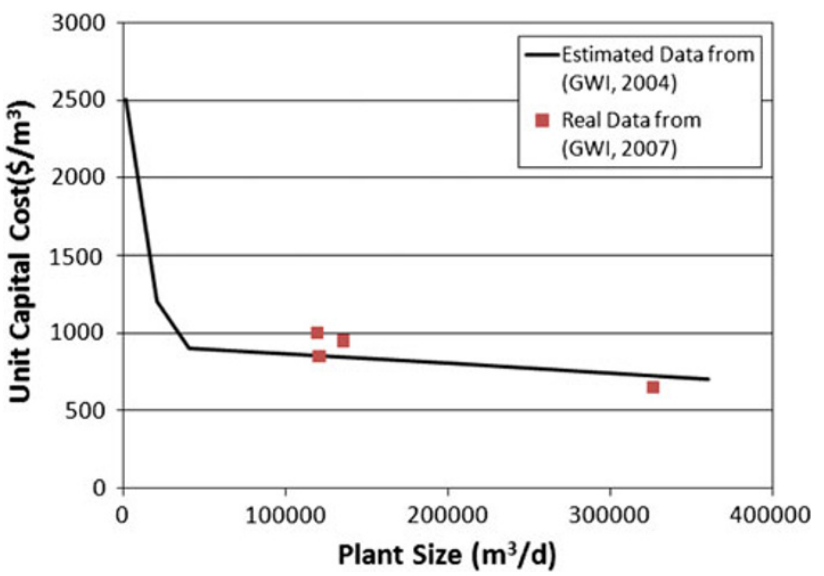

Fig. 2 SWRO plant size and capital cost

\section{Large scale}

Scale-up is one of $3 \mathrm{~L}$ (i.e., large scale) strategies and regarded as the most important goal of SEAHERO program. Plant scale-up of SWRO is advantageous in terms of economies-of-scale, which can contribute to a considerable reduction in the cost of water production as shown in Fig. 2 (GWI 2004, 2007).

The plant size is one of the most influential factors to determine the water production cost although there are many other parameters, for example, total dissolved solid (TDS) of feed seawater, water production quality (i.e., permeate TDS), seawater temperature, seawater quality, and so forth. Large SWRO plants are able to use larger, more efficient high pressure (HP) pump units and energy recovery devices (ERD) contributing to the lower energy/ operating costs of the system, which is another benefit of scale-up as shown in Table 1, which is an estimated result of energy consumption as a function of plant size (GWI 2009b). 
Table 1 Energy consumption in SWRO plant as a function of plant size

\begin{tabular}{llll}
\hline & $\begin{array}{l}0.3 \mathrm{MGD} \\
\left(1,135 \mathrm{~m}^{3} / \text { day }\right)\end{array}$ & $\begin{array}{l}10 \mathrm{MGD} \\
\left(37,850 \mathrm{~m}^{3} / \text { day }\right)\end{array}$ & $\begin{array}{l}50 \mathrm{MGD} \\
\left(189,250 \mathrm{~m}^{3} / \text { day }\right)\end{array}$ \\
\hline RO process & $10.5(2.78)$ & $8.6(2.27)$ & $7.6(2.0)$ \\
Intake & $2.01(0.53)$ & $1.74(0.46)$ & $1.72(0.45)$ \\
Pre-treat & $1.06(0.28)$ & $0.91(0.24)$ & $0.90(0.24)$ \\
Post-treat & $0.23(0.06)$ & $0.17(0.05)$ & $0.16(0.04)$ \\
Distribution & $1.17(0.31)$ & $0.86(0.23)$ & $0.85(0.23)$ \\
Total energy & $15.0(3.96)$ & $12.3(3.25)$ & $11.3(2.99)$ \\
\hline
\end{tabular}

All values in $\mathrm{kWh} / \mathrm{kgal}\left(\mathrm{kWh} / \mathrm{m}^{3}\right)$

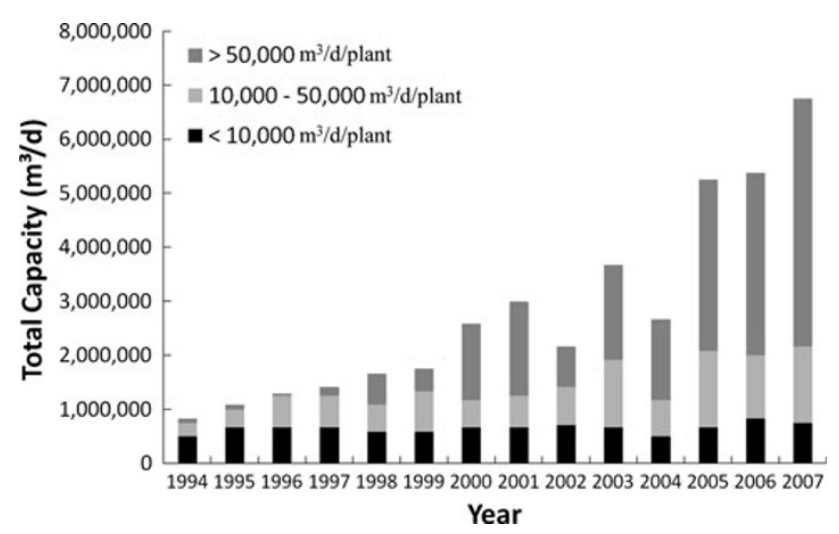

Fig. 3 Statistics of world market for SWRO plant and the market shares by plant size

Because of these benefits of scale-up, the share of large SWRO plant becomes bigger in the world desalination market as shown in Fig. 3 (GWI 2009b).

In principle, there are two approaches of system scaleup. One is the increase of size of a single component which constitutes the system, and the other is the increase of the number of the components. The three important components for SWRO system scale-up are SWRO membrane, HP pump, and ERD. HP Pump supplies relevant transmembrane pressure and flow rate to SWRO unit train, which is defined as a physically packed group of pressure vessels arranged in parallel. An HP pump unit consists of one HP pump or several HP pumps, and a pressure vessel generally consists of 6-8 membrane modules (Jacangelo 2006; Bruno 2007; Wilf 2009). ERD transfers the energy from the concentrate stream directly to feed flow to RO unit train. The capacity of HP pump and ERD is highly related to the size of SWRO unit train. Therefore, the key factor to increase SWRO plant size is dependent upon selecting appropriate the size of SWRO unit train. According to a rigorous technical review in a previous research (Kim et al. 2009a), the most efficient way to increase SWRO plant size turns out to be increasing the size of SWRO unit train. The trend of change in the unit train size from 1982 supports this conclusion as shown in Fig. 4 (GWI 2007). The test-bed of SEAHERO contains the biggest SWRO unit train (size $=8$ MIGD or $36,000 \mathrm{~m}^{3} /$ day).

Introduction of 16 in. diameter SWRO membrane will accelerate the economies-of-scale in large SWRO plant. A 16 in. diameter SWRO module can produce more than three times larger amount of fresh water than an $8 \mathrm{in}$. diameter module, which is current market standard of spiral wound RO module (Kim et al. 2009a). The diameter of 16 in. RO module assures more than $10 \%$ of capital cost saving compared to the case of $8 \mathrm{in}$. diameter module (Hallan et al. 2008). One of the most splendid products of SEAHERO is the production of $16 \mathrm{in}$. SWRO membrane module with high permeability. The production rate and the nominal salt rejection of the module is $136.1 \mathrm{~m}^{3} /$ day and $99.7 \%$ in the test condition of $32,000 \mathrm{mg} / \mathrm{l}$ sodium chloride solution, $8 \%$ of recovery, $25^{\circ} \mathrm{C}$ of temperature and 6.5-7.0 of $\mathrm{pH}$ as reported in the web page of CSM filter (http://www.csmfilter.com/upload/csm/swe/prod1_20101141 34121.pdf), which is a company member of SEAHERO. This SEAHERO-brand SWRO membrane module will be installed in the test-bed.

In summary, SEAHERO focuses on the two approaches to achieve the large-scale objective; the increases in the unit SWRO train size and the RO module diameter were shown in Fig. 5.

\section{Low fouling}

Membrane fouling has been a critical problem in worldwide desalination plants using RO membrane to separate salts from seawater (Barger and Carnahan 1991). Since the membrane fouling leads to performance deterioration such as lowered permeate flux and salt rejection, it has been hindering RO application (Tang et al. 2010). In order to reduce the membrane fouling, numerous research topics have been studied such as mechanism of membrane

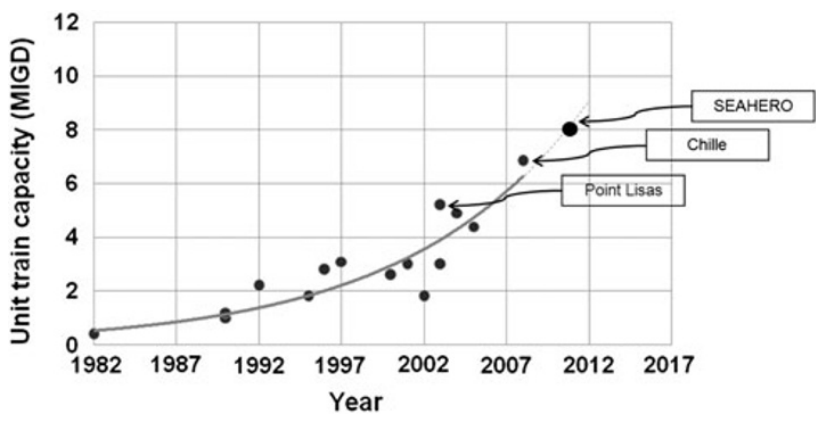

Fig. 4 The increase in the size of SWRO unit train 


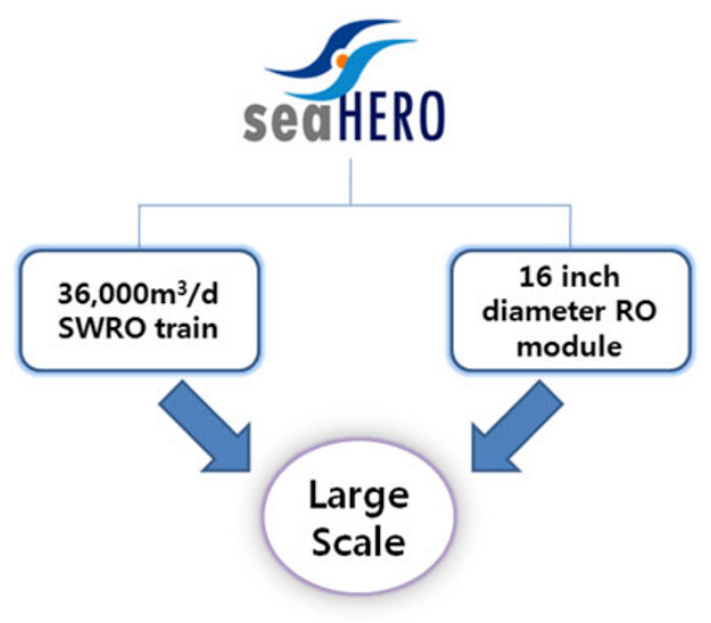

Fig. 5 The large-scale strategy in SEAHERO

fouling, optimization pre-treatment process or system, development of cleaning method or materials, development of membrane fouling index, and others (Prihasto et al. 2009)

In SEAHERO, the specific target for the low-fouling strategy is $50 \%$ of fouling reduction as mentioned in "Introduction" part of this paper. Fouling reduction in principle can be interpreted to the increase in membrane replacement period. The assurances of $50 \%$ increased membrane replacement period can be a reasonable specific target for low fouling. However, the membrane replacement period (usually more than 5 years) cannot be estimated during the R\&D period of SEAHERO until 2012. The product of SEAHERO should be estimated by Korean government at the end of the R\&D period since SEAHERO is a government-funded $\mathrm{R} \& \mathrm{D}$ program. Therefore, $50 \%$ reduction of silt density index (SDI) and a new fouling index developed in SEAHERO is selected as a specific target for low fouling instead the increase in membrane replacement period.

A number of technologies for fouling reduction can be categorized into three parts: (1) pretreatment, (2) system monitoring, and (3) manufacturing low-fouling membrane. A strategic selection of pretreatment increases the quality of RO feed water to reduce fouling. A reliable system monitoring detects fouling in early state to avoid severe irreversible fouling. Low-fouling membrane is more resistant to the attachment of foulants such as particles, organic matters, and microbes. Among these three strategies, SEAHERO focuses on pretreatment and system monitoring as shown in Fig. 6.

There are lots of unit processes for pretreatment system. The most important thing in design of pretreatment system is to select best combinations of these unit processes targeting highest RO feed water quality with lowest cost,

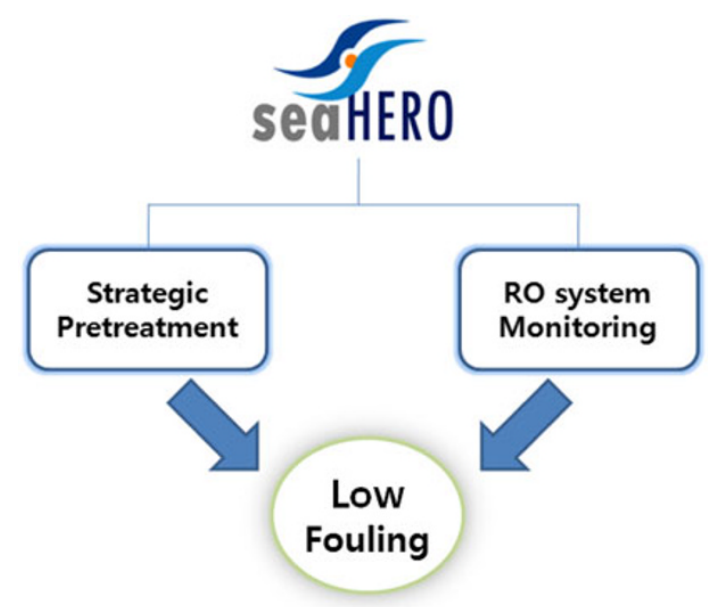

Fig. 6 The low-fouling strategy in SEAHERO

which can be called strategic pretreatment. Selection of good combinations of pretreatment processes depends on field conditions such as feed water quality, temperature, and fouling durability of RO membrane. In SEAHERO program, factors affecting design of optimal pretreatment strategies and the economic evaluation of SWRO system with regard to various antifouling strategies were investigated (Prihasto et al. 2009; Choi et al. 2009a, b, c; Jeong et al. 2010).

Reliable system monitoring technologies for SWRO system can be applied to avoid severe troubles such as irreversible fouling, scaling, and unexpected system failures, which will be more promising. In SEAHERO program, estimation technologies of system performance by using plant operation data (i.e., pressure, flow rate, temperature, total dissolved solids concentration, and $\mathrm{pH}$ ) were developed (Kim et al. 2009f, 2011), and application of biosensor to select the most problematic biofoulant in SWRO processes were investigated (Lee et al. 2009a, b).

In SEAHERO, a new fouling index was developed in order to support to achieve the strategic pretreatment and reliable system monitoring. It gives information on fouling potential by particles, hydrophilic organic matters, and hydrophobic organic matters, respectively (Choi et al. 2009a, b, c; Yu et al. 2010; Hong et al. 2010). The new fouling index is expected to be more useful than common indices such as silt density index (SDI) and modified fouling index (MFI) as well as MFI-UF and MFI-NF. In addition, more fundamental efforts to elucidate fouling mechanisms were made by developing new and advanced membrane characterization techniques such as atomic force microscopy (AFM) and dynamic hysteresis analysis (DH) (Yang et al. 2010; Lee et al. 2011). 


\section{Low energy}

Low energy can be considered as an ultimate goal of SWRO plant. Moreover, the major contributions of large scale and low fouling are saving energy consumption. The power demand of SWRO system can be affected by internal parameters (e.g., membrane permeability, HP pump, ERD, and plant size) and external parameters (e.g., seawater temperature). Higher membrane permeability assures larger amount of fresh water production per unit applied pressure, which results in less energy consumption per unit water production. The higher efficiencies in HP pump and ERD play important roles to save energy in SWRO plant. HP pump efficiency is a function of its capacity. The most efficient HP pump is installed in Ashkelon SWRO plant with efficiency of $88.5 \%$ and capacity of 12.5 MIGD (Bruno 2007). There are two types of ERD: turbine type and isobaric. Isobaric ERD has higher efficiency than turbine type ERD as shown in Table 2 (Stover 2006) although the former is more expensive than the latter in a small system. Larger plant size is more advantageous to save energy as shown in Tables 1 and 2 . High seawater temperature increases the membrane permeability to decrease the amount of energy consumption per fresh water production.

In SEAHERO, specific target for low energy is energy consumption of the test-bed including intake, pretreatment, and SWRO system less than $4 \mathrm{kWh} / \mathrm{m}^{3}$, which is not the smallest value among SWRO plants in the world. There are several SWRO plants whose total power demands are less than $4 \mathrm{kWh} / \mathrm{m}^{3}$. These plants are large in capacity and under the high temperature condition (e.g., higher than $25^{\circ} \mathrm{C}$ ). Considering the test-bed size is rather small and seawater temperature in South Korea varies from 2 to $28^{\circ} \mathrm{C}$, the target of $4 \mathrm{kWh} / \mathrm{m}^{3}$ can be a challenging objective. Moreover, the power demand of Fukuoka SWRO plant with capacity of $50,000 \mathrm{~m}^{3} /$ day, which is exactly the same as the SEAHERO test-bed, was reported as $5.5 \mathrm{kWh} / \mathrm{m}^{3}$ (GWI 2007).

Figure 7 shows the strategy of SEAHERO to achieve the low-energy objective. SEAHERO focuses on the development of high efficiency HP pump and ERD, highly permeable SWRO membrane, and system optimization. In addition, large scale and low-fouling strategies supports to achieve the low-energy objective. SEAHERO developed

Table 2 Energy consumption $\left(\mathrm{kWh} / \mathrm{m}^{3}\right)$ of SWRO system according to ERD type and system size

\begin{tabular}{lll}
\hline ERD type & Small SWRO system & Large SWRO system \\
\hline Turbine type & $4.29-4.35$ & $2.42-3.19$ \\
Isobaric & 3.45 & $1.92-2.79$ \\
\hline
\end{tabular}

an HP pump and a non-rotating isobaric ERD with efficiencies more than 85 and $95 \%$, respectively. As discussed earlier, the SEAHERO-brand 16 in. diameter SWRO module with high permeability was developed to decrease energy consumption per water production. The simulated energy consumption of the SEAHERO test-bed using these membranes was about $3.8 \mathrm{kWh} / \mathrm{m}^{3}$.

System optimization is based on the fundamental understanding of SWRO system, and a good simulator can give a good strategy for energy saving such as control of operation conditions (i.e., selection of optimal recovery rate and trans-membrane pressure in accordance with feed water quality and temperature). In SEAHERO program, various types of simulators for monitoring and prediction of SWRO process performance and cost estimation were developed (Kim et al. 2009b, c, d, e; Lee et al. 2009a, b; Oh et al. 2009). Using these simulators, several energy-saving methodologies were suggested using stochastic control approaches which considered feed water temperature and operating pressure as control parameters. The methodologies showed how to improve the performance of SWRO desalination process as well as how to save the energy during the operation of the SWRO systems.

Together with the simulation techniques, an IT-based technology for real-time monitoring of energy consumption in SWRO plants has been developed in SEAHERO program, which enables a precise control of energy usage. Small-size digital power meters coupled with a wireless communication module were designed and developed to send real-time information on electricity usage of important equipments (i.e., high pressure pump, ERD booster pump, intake, and pretreatment pumps, etc.). The information obtained by these wireless power meters can be used to operate a SWRO plant with the optimized energy consumption. Furthermore, a preventive maintenance of

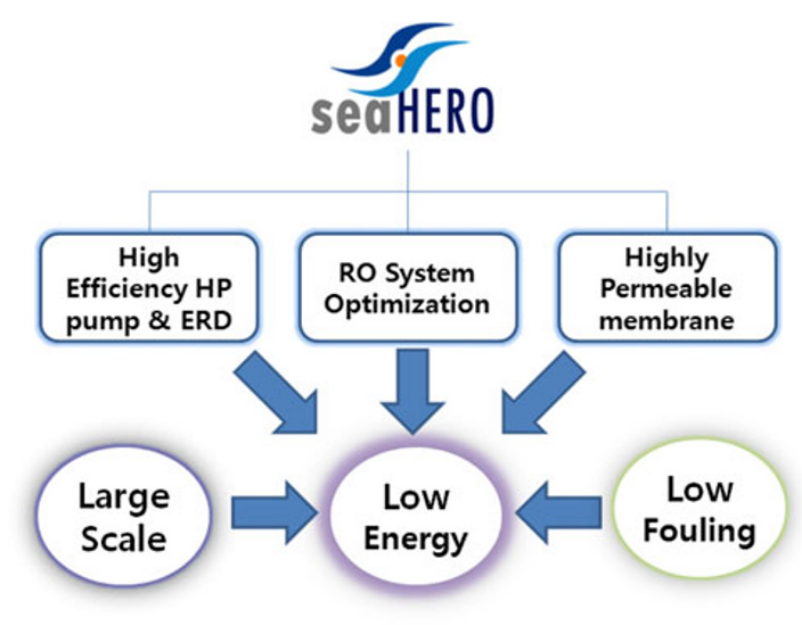

Fig. 7 The low-energy strategy in SEAHERO 
Fig. 8 The flow diagram of the SEAHERO test-bed

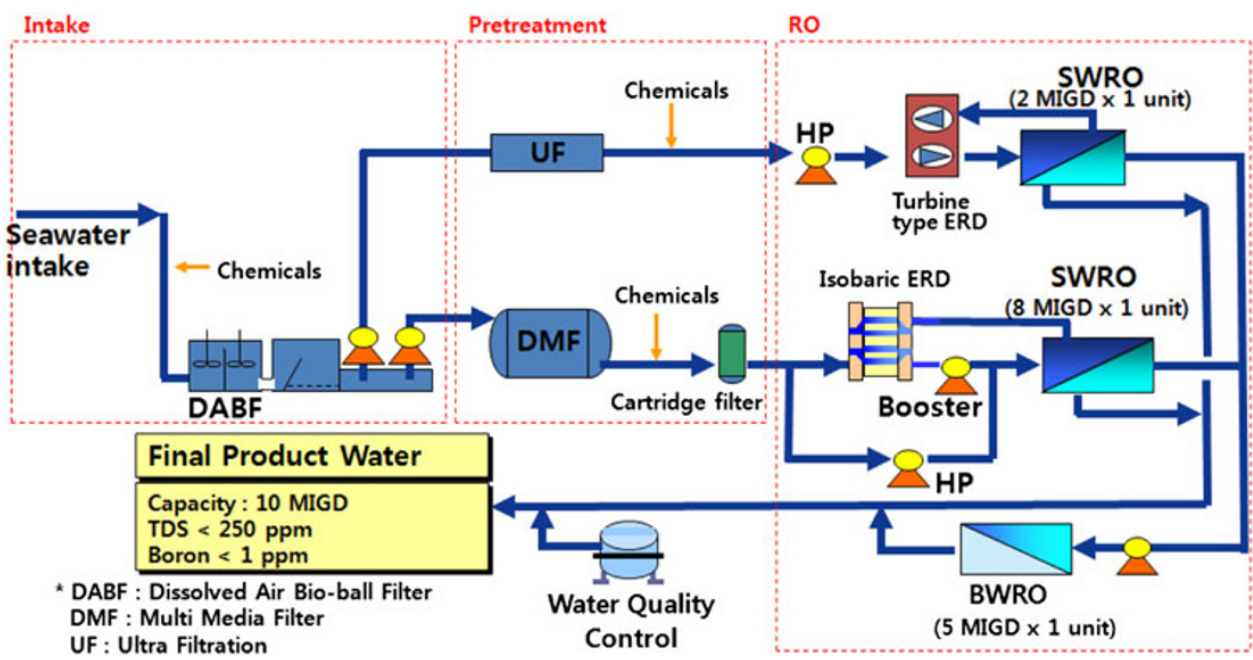

the equipments is possible by analyzing this real-time energy usage information.

In order to get further, SEAHERO carried out the researches on the combination of $\mathrm{RO}$ and forward osmosis (FO). As a result, application of FO to brine treatment was investigated (Tang and $\mathrm{Ng}$ 2008; Tan and $\mathrm{Ng}$ 2008), and the combination of RO and FO can result in more energysaving compared to conventional RO system (Choi et al. 2009a, b, c).

\section{Conclusion: the next step of SEAHERO}

SEAHERO achieved fruitful results targeting 3L (i.e., large scale, low fouling, and low energy) of SWRO plant so far and is going to leap to the world best R\&D program for seawater desalination. The next step of SEAHERO program is real field application of the $3 \mathrm{~L}$ technologies to the SEAHERO test-bed. The capacity of the test-bed is 10 MIGD (45,000 $\mathrm{m}^{3} /$ day). The test-bed will include an 8 MIGD unit SWRO train, which will be the largest unit train in the world. Currently, the test-bed is ready to be constructed in Busan, South Korea by Doosan heavy industries and construction Co. Ltd, which is in charge of CT 3 (EPC) and CT 4 (O\&M) in SEAHERO. Various pretreatment options such as coagulation, flotation, media filtration and membrane filtration, and different types of ERD (i.e., turbine type and isobaric) will be tested using the test-bed as shown in Fig. 8. Besides, process optimization based on system monitoring technologies will be verified.

The SEAHERO test-bed has two distinguished features. First, it has the world largest unit RO train as discussed earlier. Second, it will be the first SWRO plant in the world, which is firstly constructed for the R\&D purpose and then used for a drinking water production facility after the R\&D period. SEAHERO is going to develop the future desalination technology step by step, remaining footprints such as the leading-edge $3 \mathrm{~L}$ technologies and the distinguished test-bed.

Acknowledgment This research was supported by a grant (07SeaHeroA01-01) from the Plant Technology Advancement Program funded by the Ministry of Land, Transport and Maritime Affairs, Korea.

Open Access This article is distributed under the terms of the Creative Commons Attribution License which permits any use, distribution and reproduction in any medium, provided the original author(s) and source are credited.

\section{References}

Barger M, Carnahan RP (1991) Fouling prediction in reverse osmosis processes. Desalination 83:3-33

Bruno SG (2007) Ashkelon desalination plant-a successful challenge. Desalination 203:75-81

Choi JS, Hwang TM, Lee SH, Hong SK (2009a) A systematic approach to determine the fouling index for a RO/NF membrane process. Desalination 238:117-127

Choi YH, Kweon JH, Kim DI, Lee S (2009b) Evaluation of various pretreatment for particle and inorganic fouling control on performance of SWRO. Desalination 247:137-147

Choi YJ, Choi JS, Oh HJ, Lee SH, Yang DR, Kim JH (2009c) Toward a combined system of forward osmosis and reverse osmosis for seawater desalination. Desalination 247:239-246

Global Water Intelligence (GWI) (2004) Desalination markets 2005-2015. A global assessment and forecast, Media Analytics Ltd., Oxford, UK

Global Water Intelligence (GWI) (2007) IDA desalination yearbook 2006-2007. Media Analytics Ltd., Oxford, UK

Global Water Intelligence (GWI) (2009a) A new dawn for desalination in Chile. http://www.globalwaterintel.com/archive/10/12/ general/a-new-dawn-for-desalination-in-chile.html

Global Water Intelligence (GWI) (2009b) IDA desalination yearbook 2008-2009. Media Analytics Ltd., Oxford, UK

Hallan M, Johnson J, Koreltz M, Peery M, Peterson G, Zhao E (2008) Design, development, and evaluation of sixteen inch diameter 
RO/NF modules. In: International congress on water management in the mining industry, Santiago, Chile, 9-11 Jul 2008

Hong IG, Ju YG, Moon EJ, Lee SY, Hong SK (2010) Sensitivity of multiple membrane array system (MMAS) with respect to organic matter characteristics. In: The 3rd international desalination workshop (IDW), 3-6 Nov 2010, Jeju, Korea

Jacangelo JG (2006) Desalination as an alternative for a new supply. In: IWA world water congress and exhibition, Beijing, China, 10-14 Sep 2006

Jeong SP, Park YH, Lee SH (2010) High flux submerged membrane pretreatment process of SWRO pilot plant. In: The 3rd international desalination workshop (IDW), 3-6 Nov 2010, Jeju, Korea

Kim S, Cho D, Lee MS, Oh BS, Kim JH, Kim IS (2009a) SEAHERO $R \& D$ program and key strategies for the scale-up of a seawater reverse osmosis (SWRO) system. Desalination 238:1-9

Kim SJ, Lee YG, Oh SH, Lee YS, Kim YM, Jeon MG, Lee SH, Kim IS, Kim JH (2009b) Energy saving methodology for the SWRO desalination process: control of operating temperature and pressure. Desalination 247:260-270

Kim SJ, Lee GL, Cho KY, Kim YM, Choi S, Kim IS, Yang DR, Kim JH (2009c) Site-specific raw seawater quality impact study on SWRO process for optimizing operation of the pressurized step. Desalination 238:140-157

Kim SJ, Oh S, Lee YG, Jeon MG, Kim IS, Kim JH (2009d) A control methodology for the feed water temperature to optimize SWRO desalination process using genetic programming. Desalination 249:190-199

Kim YM, Lee YS, Lee YG, Kim SJ, Yang DR, Kim IS, Kim JH (2009e) Development of package model for process simulation and cost estimation of seawater reverse osmosis desalination plant. Desalination 247:326-335

Kim DY, Lee MH, Lee SH, Kim JH, Yang DR (2009f) Online estimation of fouling development for SWRO system using real data. Desalination 247:200-209

Kim S, Kang LS, Mitra SS, Jang JH, Choi JS, Lee S (2011) An intelligent diagnosis algorithm for reverse osmosis membrane performance in real field application. In: Australian Water
Association Membrane and Desalination Specialty IV conference, Gold Coast, Australia, 9-11 Feb 2011

Lee JW, Jung JY, Kim SY, Chang IS, Mirta SS, Kim IS (2009a) Selection of the most problematic biofoulant in fouled RO membrane and the seawater intake to develop biosensors for membrane biofouling. Desalination 247:125-136

Lee YG, Lee YS, Jeon JJ, Lee S, Yang DR, Kim IS, Kim JH (2009b) Artificial neural network model for optimizing operation of a seawater reverse osmosis desalination plant. Desalination 249:180-189

Lee S, Lee E, Elimelech M, Hong S (2011) Membrane characterization by dynamic hysteresis: measurements, mechanisms, and implications for membrane fouling. J Membr Sci 366:17-24

Oh HJ, Hwang TM, Lee SH (2009) A simplified simulation model of RO Systems for seawater desalination. Desalination 238:128-139

Prihasto N, Liu QF, Kim SH (2009) Pre-treatment strategies for seawater desalination by reverse osmosis system. Desalination 247:308-316

Stover RL (2006) Energy recovery devices for seawater reverse osmosis. EverythingAboutWater, November, 2006, pp 40-44

Tan CH, Ng HY (2008) Modified models to predict flux behavior in forward osmosis in consideration of external and internal concentration polarizations. J Membr Sci 324:209-219

Tang W, Ng HY (2008) Concentration of brine by forward osmosis: performance and influence of membrane structure. Desalination 224:143-153

Tang CY, Chong TH, Fane AG (2010) Colloidal interactions and fouling of $\mathrm{NF}$ and $\mathrm{RO}$ membranes: a review. Adv Colloid Interface Sci (in press)

Wilf M (2009) The guidebook to membrane desalination technology. Balaban Desalination Publications, Italy

Yang J, Lee S, Yu Y, Kuk J, Hong S, Lee S, Min K (2010) Role of foulant-membrane interactions in organic fouling of RO membranes with respect to membrane properties. Sep Sci Technol 45:948-955

Yu YB, Lee SY, Hong KW, Hong S (2010) Evaluation of membrane fouling potential by multiple membrane array system (MMAS): measurements and applications. J Membr Sci 362:279-288 